Subscriber access provided by SCD Université de Rennes1 | SCD de l'Université de Rennes 1

Article

\title{
Co-binding of pharmaceutical compounds at mineral surfaces: Molecular investigations of dimer formation at goethite/water interfaces
}

Jing Xu, Rémi Marsac, Dominique Costa, Wei Cheng, Feng Wu, Jean-François Boily, and Khalil Hanna

Environ. Sci. Technol., Just Accepted Manuscript • DOI: 10.1021/acs.est.7b02835 • Publication Date (Web): 03 Jul 2017

Downloaded from http://pubs.acs.org on July 6, 2017

\section{Just Accepted}

"Just Accepted" manuscripts have been peer-reviewed and accepted for publication. They are posted online prior to technical editing, formatting for publication and author proofing. The American Chemical Society provides "Just Accepted" as a free service to the research community to expedite the dissemination of scientific material as soon as possible after acceptance. "Just Accepted" manuscripts appear in full in PDF format accompanied by an HTML abstract. "Just Accepted" manuscripts have been fully peer reviewed, but should not be considered the official version of record. They are accessible to all readers and citable by the Digital Object Identifier (DOI®). "Just Accepted" is an optional service offered to authors. Therefore, the "Just Accepted" Web site may not include all articles that will be published in the journal. After a manuscript is technically edited and formatted, it will be removed from the "Just Accepted" Web site and published as an ASAP article. Note that technical editing may introduce minor changes to the manuscript text and/or graphics which could affect content, and all legal disclaimers and ethical guidelines that apply to the journal pertain. ACS cannot be held responsible for errors or consequences arising from the use of information contained in these "Just Accepted" manuscripts. 

8

\section{Co-binding of pharmaceutical compounds at mineral surfaces: Molecular investigations of dimer formation at goethite/water interfaces}

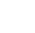

${ }^{a}$ State Key Laboratory of Water Resources and Hydropower Engineering Science,

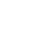

(n)
${ }^{b}$ Ecole Nationale Supérieure de Chimie de Rennes, CNRS, UMR 6226, 11 Allée de Beaulieu, CS 50837, 35708 Rennes Cedex 7, France.

${ }^{\mathrm{c}}$ Institut de Recherches de Chimie de Paris UMR 8247 ENSCP Chimie Paristech, 11 rue P. Et M. Curie, 75005 Paris, France.

${ }^{\mathrm{d}}$ Hubei Key Lab of Biomass Resource Chemistry and Environmental Biotechnology, School of Resources and Environmental Science, Wuhan University, Wuhan, 430079, P. R. China. ${ }^{\mathrm{e}}$ Department of Chemistry, Umeå University, Umeå, SE-901 87, Sweden *Corresponding author: Tel.: +33 2232380 27, khalil.hanna@ensc-rennes.fr

"Present address: Géosciences Rennes, UMR CNRS 6118, Université de Rennes 1, Campus de Beaulieu, CS74205, 35042 Rennes Cedex, France A manuscript re-submitted to $E S \& T$

June, 2017 


\section{Abstract}

The emergence of antibiotic and anti-inflammatory agents in aquatic and terrestrial systems is becoming a serious threat to human and animal health worldwide. Because pharmaceutical compounds rarely exist individually in nature, interactions between various compounds can have unforeseen effects on their binding to mineral surfaces. This work demonstrates this important possibility for the case of two typical antibiotic and anti-inflammatory agents (nalidixic acid (NA) and niflumic acid (NFA)) bound at goethite $(\alpha-\mathrm{FeOOH})$ used as a model mineral surface. Our multidisciplinary study, which makes use of batch sorption experiments, vibration spectroscopy and periodic density functional theory calculations, reveals enhanced binding of the otherwise weakly bound NFA caused by unforeseen intermolecular interactions with mineral-bound NA. This enhancement is ascribed to the formation of a NFA-NA dimer whose energetically favoured formation $(-0.5 \mathrm{eV}$ compared to free molecules $)$ is predominantly driven by van der Waals interactions. A parallel set of efforts also showed that no co-binding occurred with sulfamethoxazole (SMX) because of the lack of molecular interactions with co-existing contaminants. As such, this article raises the importance of recognising drug co-binding, and lack of co-binding, for predicting and developing policies on the fate of complex mixtures of antibiotics and anti-inflammatory agents in nature. 


\section{Introduction}

$$
\text { Thousands of different emerging pharmaceutical contaminants occur in soils, }
$$
groundwater, surface waters as well as seawater from human and intensive farming activities. $^{1,2}$ Antibiotics and anti-inflammatory agents in terrestrial and aquatic environments, in some instances at levels as high as several hundred ng per $\mathrm{L}^{3-6}$ are posing detrimental ecological and health effects especially because of their growing use in human and veterinary medicine. Because the fate of these compounds is often tied to their affinities to surfaces of soil and sediment mineral particles ${ }^{7,8}$, adsorption through synergistic drug interactions is likely to become an emerging mechanism in contaminated environments.

Although contaminants rarely exist in isolation, they often have been studied individually with respect to sorption and/or complexation with naturally occurring minerals. ${ }^{9-12}$ Sorption of individual compounds to environmental surfaces involves different mechanisms including metal bond, hydrogen bond, and van der Waals interactions ${ }^{13}$. In multicomponent systems, co-existing contaminants can compete for surface binding sites, or cooperatively bind by co-neutralisation of surface charge and/or by direct molecular interactions. While competitive adsorption has been widely investigated $^{14-16}$, cooperative effects have been never reported for widely used antibiotic and anti-inflammatory agents. In addition, because most traditional environmental models are based on an individual contaminant basis, little is known on their fate in mixed contaminant systems. 
In this work, we assessed the ability of three typical antibiotic and anti-inflammatory agents detected in affected environments ${ }^{6,17}$ (nalidixic acid (NA), niflumic acid (NFA) and sulfamethoxazole (SMX)) to co-bind at minerals surfaces. Goethite $(\alpha-\mathrm{FeOOH})$ is selected as model mineral because it is one of the most stable thermodynamically iron oxyhydroxide at ambient temperature and the most abundant one in natural settings. NA is a quinolone antibiotic that is widely used in humans and animals and that typically co-occurs with SMX, a sulfonamide antibiotic commonly used to treat a variety of bacterial infections ${ }^{18}$. Niflumic acid (NFA) is a non-steroidal anti-inflammatory that is often used for rheumatoid arthritis. ${ }^{19}$ As will be detailed in this work, investigations are mainly focused on NA and NFA as no co-binding effect are typically observed with SMX. Vibration spectroscopic and density functional theory (DFT) calculations of NA/NFA co-binding, as well as batch kinetic, pH-edges and isotherms, were used to resolve uptake mechanisms of NA and NFA at goethite in isolated $v s$. mixed systems. These efforts helped identify conditions under which drug co-binding is likely to prevail in the environment.

\section{Experimental Methods}

Materials and chemicals. Nalidixic acid (NA), Niflumic acid (NFA), Sulfamethoxazole $(\mathrm{SMX})$, sodium chloride $(\mathrm{NaCl})$, potassium hydroxide $(\mathrm{KOH})$, sodium hydroxide $(\mathrm{NaOH})$ and hydrochloric acid $(\mathrm{HCl})$ were obtained from Sigma Aldrich, and were of analytical grade or better. The preparation and characteristics of goethite are detailed in the supporting information (SI). 
87

\section{Binding and co-binding experiments}

88

Kinetic adsorption experiments were conducted in $125 \mathrm{~mL}$ Nalgene bottles containing $0.5 \mathrm{~g} / \mathrm{L}$ goethite in $10 \mathrm{mM} \mathrm{NaCl}$ under an atmosphere of $\mathrm{N}_{2}(\mathrm{~g})$. NA, NFA and SMX concentrations were of $20 \mu \mathrm{M}$ in both isolated (NA; NFA; SMX) and mixed (NA+NFA; NA+SMX, NFA+SMX) systems. pH was adjusted using dilute $\mathrm{NaOH}$ or $\mathrm{HCl}$ solutions to a pre-selected value. Aliquots were sampled during the course of the experiments and filtered $(0.2 \mu \mathrm{m})$ for analysis. Preliminary experiments showed that adding the ligand simultaneously or sequentially after several hours of equilibration had no significant effects on adsorption results.

Equilibrium adsorption experiments as a function of $\mathrm{pH}(4<\mathrm{pH}<9)$ were conducted in $15 \mathrm{~mL}$ polypropylene tubes under an atmosphere of $\mathrm{N}_{2}(\mathrm{~g})$ to minimize interferences with dissolved $\mathrm{CO}_{2}$ at $\mathrm{pH}>6.5$ (Fig. S1). Adsorption isotherms were, in turn, recorded at $\mathrm{pH}=6$ under $\mathrm{N}_{2}(\mathrm{~g})$ for (i) equimolar concentrations of NA and NFA $(0.1-40 \mu \mathrm{M})$, (ii) $[\mathrm{NA}]_{\mathrm{tot}}=20 \mu \mathrm{M}$ and varying $[\mathrm{NFA}]_{\text {tot }}(0.1-40 \mu \mathrm{M})$, and (iii) $[\mathrm{NFA}]_{\mathrm{tot}}=20 \mu \mathrm{M}$ and varying $[\mathrm{NA}]_{\mathrm{tot}}(5-40 \mu \mathrm{M})$. The adsorbed amount was calculated by depletion method. Desorption tests were also conducted at $\mathrm{pH}=11$ to check the mass balance, and an average recovery of $99 \pm 2 \%$ for the investigated solutes was obtained (see SI). Sorption and desorption experiments were performed at least twice, and the reproducibility of the measurements was around 5\% for NA and 10\% for NFA.

Aqueous concentrations of organic molecules were determined using a high performance liquid chromatography (Waters 600 Controller) equipped with a 
reversed-phase $\mathrm{C} 18$ column $(250 \mathrm{~mm} \times 4.6 \mathrm{~mm}$ i.d., $5 \mu \mathrm{m})$ and a photodiode array detector (Waters 996). The mobile phase was mixture of acetonitrile/water (60/40v/v) contained $0.1 \%$ formic acid. The flow rate was set at $1 \mathrm{~mL} / \mathrm{min}$ in isocratic mode. The detector was set to $258 \mathrm{~nm}$ for NA, $283 \mathrm{~nm}$ for NFA and $270 \mathrm{~nm}$ SMX. All three molecules could be analyzed with a single injection because they exhibited different retention times (NA: 4.5 min; NFA: $10.1 \mathrm{~min}$; SMX: $3.2 \mathrm{~min}$ ).

\section{ATR-FTIR spectroscopy and MCR analysis}

Attenuated total reflectance-Fourier transform infrared (ATR-FTIR) spectra were recorded between in the $780-4000 \mathrm{~cm}^{-1}$ region on an IS50 Nicolet spectrometer equipped with a $\mathrm{KBr}$ beam splitter and a liquid nitrogen cooled MCT detector. A nine-reflection diamond ATR accessory (DurasamplIR ${ }^{\mathrm{TM}}$, Sens IR Technologies) was used for acquiring spectra of wet samples. The resolution of the single beam spectra was $4 \mathrm{~cm}^{-1}$.

Sample preparation for the ATR-FTIR analysis was the same as for batch sorption experiments and has described in detail in our previous work ${ }^{20}$. Spectra of goethite suspensions in $10 \mathrm{mM} \mathrm{NaCl}$ were also taken in the absence of NA and NFA and then subtracted from the spectra of sorbed NA and/or NFA in order to represent surface complexes only. Two series of experiments were conducted at $\mathrm{pH}=6$ in $10 \mathrm{mM} \mathrm{NaCl}$ for $0.5 \mathrm{~g} / \mathrm{L}$ goethite and (i) $0<[\mathrm{NFA}]_{\text {tot }}<100 \mu \mathrm{M}$ with $[\mathrm{NA}]_{\text {tot }}=100 \mu \mathrm{M}$ or (ii) $0<$ $[\mathrm{NA}]_{\text {tot }}<100 \mu \mathrm{M}$ with $[\mathrm{NFA}]_{\text {tot }}=100 \mu \mathrm{M}$. Due to the relatively low solubility of both

NA and NFA (see SI), $1 \mathrm{M} \mathrm{NaOH}$ was used to dissolve NA or NFA to ensure a high 
131

132

concentration (10 mM) for ATR-FTIR analysis of NA and NFA aqueous solution. The solid form of NA and NFA was also analysed using ATR-FTIR by loading powder on the crystal, and then a drop of water was added to apply it more uniformly. Additionally, the effect of $\mathrm{pH}$ (4-6) on NA and NFA sorption to goethite in $10 \mathrm{mM} \mathrm{NaCl}$ was investigated for $[\mathrm{NA}]_{\mathrm{tot}}$ or $[\mathrm{NFA}]_{\mathrm{tot}}=100 \mu \mathrm{M}$ as described in supporting information (SI).

Selected sets of ATR-FTIR spectra in the $1200-1700 \mathrm{~cm}^{-1}$ region were then analyzed by multivariate curve resolution (MCR) analysis ${ }^{21}$. These efforts extracted spectral profiles and their relative concentrations (FTIR measurements cannot be used to obtain absolute concentration values) of end-member components representing an assemblage of the purest chemical species possible. Spectra sets were expressed in the matrix $\mathbf{A}$ ( $m$ rows of wavenumber and $n$ columns of measurements), and offset to zero absorbance at $1700 \mathrm{~cm}^{-1}$, where absorption by the wet mineral pastes is constant. The spectra were expressed in terms of a linear combination of spectral profiles $(\varepsilon)$, akin to molar absorption coefficients, and their concentration profiles $(\mathbf{C})$, and are related by $\mathbf{A}=\boldsymbol{\varepsilon} \mathbf{X}$ as in the Beer-Lambert law, such that that $\boldsymbol{\varepsilon} \geq 0$ and $\mathbf{C} \geq 0$. Calculations of $\boldsymbol{\varepsilon}$ and C were made with the MCR-ALS program ${ }^{21}$ in the computational environment of MATLAB (The Mathworks, Inc.). No assumptions regarding the spectroscopic responses of the different species are made through this process. 
153

154

155

156

157

158

159

160

161

162

163

164

165

166

167

168

169

170

171

172

\section{DFT Calculations}

$\mathrm{DFT}+\mathrm{D}$ calculations were performed using an ab initio plane-wave pseudopotential approach as implemented in VASP. ${ }^{22,23}$ The Perdew-Burke-Ernzerhof (PBE) functional $^{24}$ was chosen to perform the periodic DFT calculations using the projector augmented-wave method (PAW) ${ }^{25}$ and a cutoff of $400 \mathrm{eV}$. The dispersion forces were taken into account using the Grimme D2 approach. ${ }^{26}$ To avoid the heavier computational treatment of magnetic and electron-correlated iron oxides, we chose to perform DFT calculations on two Al oxy-hydroxides (non-magnetic compounds): (i) diaspore $(\alpha-\mathrm{AlOOH})$ which is the $\mathrm{Al}(\mathrm{III})$ isomorph of goethite, and (ii) gibbsite $\left(\mathrm{AlOH}_{3}\right)$ because the co-binding phenomenon is experimentally shown on this mineral surface (See SI). This allowed also to perform more extensive calculations.

The bulk gibbsite and bulk diaspore were optimized and a $(2 \times 2)$ and a $(4 \times 4)$ cell was chosen to build the basal surfaces, respectively. Then the molecules were optimized separately in the same supercell as that used to model the surface, and the dimer was also studied. Several protonation states of the NFA were considered. Since the determination of adsorption free energy from water phase was not the aim of our study, the solvent water molecules were not included in the calculations. The adsorption energies computed here inform rather on the molecule-surface interaction strength. The detailed calculation results are detailed in the SI. 
173

174

175

176

177

178

179

180

181

182

183

184

185

186

187

188

189

190

191

192

193

194

\section{Results and Discussion}

Macroscopic assessment of NA and NFA binding. Binding kinetics of NA and NFA in both single and binary systems followed pseudo-second-order kinetic model (Fig. S3) and displayed comparable behaviours, with NA binding more strongly than NFA. However, NFA loadings were considerably enhanced in the presence of NA, thus providing a first line of evidence for synergetic intermolecular interactions at mineral surfaces (SI). This can also be appreciated by $\sim 4$-fold slower adsorption rate of NFA in the mixed system (pseudo-second order rate constant of $0.16 \mathrm{~m}^{2} / \mu \mathrm{mol} \cdot \mathrm{min}$ ) than in the isolated system $\left(0.60 \mathrm{~m}^{2} / \mu \mathrm{mol} \cdot \mathrm{min}\right)$. In contrast, mixed systems containing SMX did not reveal any co-binding effects (Fig. S4).

NA and NFA binding at mineral surfaces in single system (Fig.1 for goethite) follows the typical $\mathrm{pH}-$ dependent behaviour of carboxylic acids. ${ }^{10,27-29} \mathrm{NA}$ adsorption was accordingly greatest under acid to circumneutral $\mathrm{pH}$, where goethite surfaces are positively charged, and NA carboxylate groups deprotonated $\left(\mathrm{pK}_{\mathrm{a}}=6.19\right.$ for NA at infinite dilution ${ }^{30,} c f$. Fig. S5). However, as NFA is a diprotic acid $\left(\mathrm{pKa}_{1}=2.28\right.$ and $\mathrm{pKa}_{2}=5.10$ at infinite dilution $)^{31}$, it can exist as cationic, zwitterionic and anionic forms.

Only $23 \%$ of NFA was sorbed at acid $\mathrm{pH}$ and this percentage decreased with $\mathrm{pH}$ increasing. Interestingly, binding of NA and NFA in mixed systems occurs over the entire $\mathrm{pH}$ 4-9 range considered in this work (Figs. 1). This cooperative effect is more pronounced for NFA because of its weaker adsorption in the isolated system (e.g. increase of adsorption from $22 \%$ to $54 \%$ at $\mathrm{pH} 5$ ). In addition, the $\mathrm{pH}$-adsorption curve of NFA (Fig.1b) becomes bell-shaped as in NA (Fig. 1a), suggesting that the NFA 
195

196

binding to goethite surfaces in the binary system is closely related to the behavior of NA binding.

Because this synergetic effect was observed for both molecules, two approaches were adopted to study NFA and NA co-binding in mixed systems. Firstly, varying the concentrations of NA and NFA, at ratio of $1: 1\left([\mathrm{NFA}]_{\mathrm{tot}}=[\mathrm{NA}]_{\mathrm{tot}}\right)$, strongly points to NA/NFA co-binding at goethite surfaces under a wide range of solute concentration (0.1 to $40 \mu \mathrm{M})$, a range that notably partially overlaps with those in aquatic environments (nM to several dozens of $n M)^{3-6}$ (Fig. 2a). Indeed, NFA and NA loadings at pH 6 in isolated systems were lower than those measured in equimolar mixtures (Fig. 2a). Interestingly, by plotting the NFA loadings versus NA loadings in equimolar mixtures, an excellent linear correlation was obtained (Fig. $2 b,[N F A]_{\mathrm{ads}}=0.6344$ $[N A]_{\mathrm{ads}}, \mathrm{R}^{2}=0.999$, fitted line was not shown). Secondly, varying $[\mathrm{NA}]_{\text {tot }}$ at constant $[\mathrm{NFA}]_{\text {tot }}(20 \mu \mathrm{M})$ and, conversely, varying $[\mathrm{NFA}]_{\text {tot }}$ at constant $[\mathrm{NA}]_{\text {tot }}(20 \mu \mathrm{M})$ showed that increasing surface loadings of one ligand increases the other. However, a plateau was reached for $[\mathrm{NFA}]_{\mathrm{ads}}$ where $[\mathrm{NA}]_{\text {tot }}$ varies, which is likely to have arisen from molecular layers acting as steric or electrostatic barriers preventing additional binding. ${ }^{32}$

Molecular investigations of co-binding. Vibration spectroscopy and density functional theory (DFT) calculations were used to provide clues on the mechanisms through which NA and NFA bind and co-bind at goethite surfaces. We note that DFT calculations were performed on diaspore (Fig. 3), which is the $\mathrm{Al}(\mathrm{III})$ isomorph of 
217 goethite, to avoid the otherwise heavier computational treatment of magnetic and 218 electron-correlated iron oxides. The (110) face was chosen to emulate the dominant 219 crystallographic face of the goethite particles under study.

220

221

222

223

224

225

226

227
The fingerprint region of these molecules $\left(1200-1800 \mathrm{~cm}^{-1}\right.$; Fig. 4, see also band assignments in SI) showed a $25 \mathrm{~cm}^{-1}$ blue shifts in $\mathrm{C}-\mathrm{O}$ stretching modes $\left(v_{\mathrm{COO}}\right)$, while no obvious shift for the ring modes $v_{\text {ring }}$ was observed. This suggests direct interactions of carboxyl groups with goethite but little interaction with the aromatic and pyridine rings during the sorption of NA and NFA in single system ${ }^{13,33}$. Though vibration spectroscopy suggests both metal- and hydrogen-bonding for NA, DFT calculations suggest that hydrogen bonding is the preferred binding mode for NA $(-0.34 \mathrm{eV} v s$. $+0.44 \mathrm{eV}$ for inner sphere complexation) and that it is $0.37 \mathrm{eV}$ more favourable than NFA $(+0.03 \mathrm{eV})$. Thus while both complexes are stabilised by direct hydrogen bonds between carboxyl groups and surface hydroxo groups, NA binding is made stronger by a vicinal carbonyl of the pyridine ring and involves a hydrogen-bond cycle between the molecule and two surface water molecules (Fig.3). In contrast, this cycle is not only absent in NFA but when we forcefully hydrogen bonded NFA with an adsorbed water simulations showed that this water reoriented itself towards a neighboring water molecule. The weak nature of NFA binding can even be compared to those of monocarboxylic acids (e.g. acetate or benzoate $\left.{ }^{13}\right)$. 
Vibration spectra of mixed NA+NFA systems exposed to goethite (Fig. 4) showed that increasing NFA concentrations $(0,10,20,50$ and $100 \mu \mathrm{M})$ with $[N A]_{\text {tot }}=100 \mu \mathrm{M}$ systematically increased the intensities of the characteristic bands of NFA $\left(v_{\mathrm{COO}, \mathrm{as}}=1480-1560 \mathrm{~cm}^{-1}\right)$, yet the resulting spectra cannot be represented as simple linear combinations of the isolated goethite-NA and goethite-NFA systems (Fig. S7a). For instance, the ring mode $\left(v_{\mathrm{C}=\mathrm{C} \text {,ring }}\right)$ of NA was shifted from $1578 \mathrm{~cm}^{-1}$ to $1522 \mathrm{~cm}^{-1}$ and that of NFA was split into two bands (1335 and $\left.1348 \mathrm{~cm}^{-1}\right)$ suggesting perturbation of $\mathrm{C}-\mathrm{C}$ stretches and/or $\mathrm{C}-\mathrm{H}$ bends of the aromatic and pyridine rings $\mathrm{s}^{34,35}$, and thus formation of dimer involving the aromatic and pyridine rings of NFA and NA. These observations also hold for the converse experiments where NA concentrations $(0,10$, $20,50$ and $100 \mu \mathrm{M})$ are increased with $[\mathrm{NA}]_{\mathrm{tot}}=100 \mu \mathrm{M}$ (Fig. S7b).

A multivariate curve resolution (MCR) analysis ${ }^{21}$ of these spectral sets provided further insight into the nature of NFA and NA co-binding. MCR decomposed each spectral sets into two separate spectral components (Figs. $5 \mathrm{a}, \mathrm{b}$ ) representing the purest extractable mineral-bound NFA and NA complexes (MCR I) and those under competing systems (MCR II). The related concentration profiles (Fig. 5c) revealed that addition of NA to mineral-bound NFA was more effective at altering the spectral profile of NFA than the converse addition of NFA to mineral-bound NA. Still, as the resulting MCR II components are markedly similar, our results suggest that the resulting surface complexes at equimolar NA and NFA levels are strongly similar irrespective of the order of addition. Finally, we note that these observations also hold for lower concentrations (Fig. S8 where $[\mathrm{NA}]_{\mathrm{tot}}=20 \mu \mathrm{M}$ and $[\mathrm{NFA}]_{\mathrm{tot}}=10-40 \mu \mathrm{M}$ ). 
In line with the concept that NA enhances NFA binding, DFT calculations reveal

261

262

263

264

265

266

267

268

269

270

271

272

273

274

275

276

277

278

279

280

281

that NFA binding to a hydrogen-bound NA on diaspore is energetically favourable $(-0.21 \mathrm{eV})$. The resulting dimer formed via favourable hydrogen bonding and van der Waals interactions by $-0.50 \mathrm{eV}$, and the two $\mathrm{COOH}$ moieties of this dimer are parallel with one another thus increasing the strengths of its interactions with mineral surfaces (cf. SI for more information and Figures S10-S15). As such, recalling that NA binding is favourable by $-0.34 \mathrm{eV}$, binding of NFA to a pre-sorbed NA should be favourable by $-0.55 \mathrm{eV}$. In comparison, NA and NFA binding at different locations on the same diaspore surface are favourable by only $-0.30 \mathrm{eV}$ and the formation an unbound NA/NFA dimer is favourable by $-0.50 \mathrm{eV}$.

Because the main mode of attachment for NA is achieved via hydrogen bonding at circumneutral conditions, this phenomenon is not only limited to strongly reactive faces of minerals, such as the (110) face of goethite/diaspore or edges of clays, but also on the basal planes of minerals. The planes are of widespread occurrence in platy metal (oxy)(hydr)oxides as well as phyllosilicates (e.g. clays) and typically display (hydr)oxo groups that are strongly resilient to ligand exchange, yet are active hydrogen bonding sites. To illustrate this point further the SI contains further details on the energetics of NA/NFA co-binding on the basal plane of gibbsite, an important aluminium hydroxide in natural but also industrial settings. Gibbsite gives more weight to our demonstration, since the NA/NFA co-binding is experimentally shown to occur on this mineral surface (See Fig. S16). 
282

283

284

285

286

287

288

289

290

291

292

293

294

295

296

297

298

299

300

301

302

Those results also fall precisely in line with those obtained for diaspore, and suggests the possibility in generalizing our finding to an even broader range of minerals and particles which capable of stabilizing NA-like molecules via hydrogen bonding. Our calculations consequently lend strong independent support for the concept that NA and NFA co-bind at mineral surfaces of even contrasting structure, and that a dimer-type species stabilized by intermolecular hydrogen bonding and van der Waals interactions could be responsible for this phenomenon.

Implications for transport of pharmaceutical compounds in nature. Our concerted macroscopic and molecular efforts both provide evidence that NFA-NA interactions mutually enhance binding at mineral surfaces such as goethite. This cooperative effect is more pronounced for NFA because of its intrinsically weaker affinity for mineral surfaces, and occurs under environmentally relevant conditions of drug concentration and $\mathrm{pH}$. Vibration spectroscopic data show that addition of NA effectively alters the nature of mineral-NFA binding but that converse addition of NFA to mineral-bound NA results in a less dramatic change in the nature of NA binding. In support to these finding DFT calculations showed that NFA binding on mineral faces of even strongly contrasting structures is thermodynamically favoured only when NA is pre-adsorbed either metal-bonded or hydrogen-bonded. This favoured form of binding could be explained by the formation of a NFA-NA dimer stabilised by hydrogen bonding and van der Waals interactions. The lack of co-binding seen in SMX also suggests the 
303

304

importance of understanding drug interactions in aqueous solutions, a finding that also calls for new studies along these lines.

This study is the first to show that mineral-bound antibiotic molecules can be specific adsorption sites for other antibiotic molecules, and that layered-like coatings involving anti-inflammatory agents may even form at mineral surfaces. As water resources are exposed to complex mixtures of chemicals ${ }^{36}$, including natural organic matter and metal ions, additional efforts resolving the underlying principles governing cooperative sorption should be made to accurately assess the fate of co-existing contaminants in the environment. This becomes even more so urgent under the growing number aquatic ecosystems and groundwater systems exposed to emerging contaminants including non-prescription drugs, antibiotics, hormones and prescription drugs $^{36,37}$. As a result, recognising the importance of drug co-binding at mineral surfaces, and the conditions where it does not occur such as in the case of SMX, is key to the successful development of models for predicting the fate of these contaminants, and for guiding policies on actions needed to mitigate this growing environmental problem.

\section{Acknowledgements}

This work was supported by Rennes Métropole and Région Bretagne (K.H). We gratefully acknowledge the Chinese Scholarship Council of PR China for providing financial support for Jing XU to stay at the ENSCR - Rennes University. Support to J.-F.B. was provided by the Swedish Research Council (2016-03808). 


\section{Supporting Information Available}

326 Details of the materials used in this study, mineral characterization, analytical and DFT

327 methods, and additional data are available in the Supporting Information. This

328 information is available free of charge via the Internet at http://pubs.acs.org/. 
330

331

332

333

334

335

336

337

338

339

340

341

342

343

344

345

346

347

348

349

350

351

\section{References}

(1) Lapworth, D. J.; Baran, N.; Stuart, M. E.; Ward, R. S. Emerging organic contaminants in groundwater: a review of sources, fate and occurrence. Environ. Pollut. 2012, 163, 287-303.

(2) Kolpin, D. W.; Furlong, E. T.; Meyer, M. T.; Thurman, E. M.; Zaugg, S. D.; Barber, L. B.; Buxton, H. T. Pharmaceuticals, hormones, and other organic wastewater contaminants in US streams, 1999-2000: A national reconnaissance. Environ. Sci. Technol. 2002, 36 (6), 1202-1211.

(3) Hernando, M. D.; Mezcua, M.; Fernández-Alba, A. R.; Barceló, D. Environmental risk assessment of pharmaceutical residues in wastewater effluents, surface waters and sediments. Talanta 2006, 69 (2), 334-342.

(4) Heberer, T. Occurrence, fate, and removal of pharmaceutical residues in the aquatic environment: a review of recent research data. Toxicol. Lett. 2002, 131 (1), 5-17.

(5) Fatta-Kassinos, D.; Meric, S.; Nikolaou, A. Pharmaceutical residues in environmental waters and wastewater: Current state of knowledge and future research. Anal. Bioanal. Chem. 2011, 399 (1), 251-275.

(6) Gothwal, R.; Shashidhar, T. Antibiotic Pollution in the Environment: A Review. CLEAN--Soil, Air, Water 2015, 43 (4), 479-489.

(7) Gu, C.; Karthikeyan, K. G. Sorption of the antimicrobial ciprofloxacin to aluminum and iron hydrous oxides. Environ. Sci. Technol. 2005, 39 (23), 9166-9173. 
352 (8) Wang, Y.; Newman, D. K. Redox reactions of phenazine antibiotics with ferric 353 (hydr) oxides and molecular oxygen. Environ. Sci. Technol. 2008, 42 (7), 2380-2386.

(9) Xu, X.-R.; Li, X.-Y. Sorption and desorption of antibiotic tetracycline on marine sediments. Chemosphere 2010, 78 (4), 430-436.

(10) Paul, T.; Liu, J.; Machesky, M. L.; Strathmann, T. J. Adsorption of zwitterionic fluoroquinolone antibacterials to goethite: A charge distribution-multisite complexation model. J. Colloid Interface Sci. 2014, 428, 63-72.

(11) Pouliquen, H.; Le Bris, H. Sorption of oxolinic acid and oxytetracycline to marine sediments. Chemosphere 1996, 33 (5), 801-815.

(12) Kulshrestha, P.; Giese, R. F.; Aga, D. S. Investigating the molecular interactions of oxytetracycline in clay and organic matter: insights on factors affecting its mobility in soil. Environ. Sci. Technol. 2004, 38 (15), 4097-4105.

(13) Norén, K.; Persson, P. Adsorption of monocarboxylates at the water/goethite interface: The importance of hydrogen bonding. Geochim. Cosmochim. Acta 2007, $71(23), 5717-5730$.

(14) Sun, D.; Zhang, X.; Wu, Y.; Liu, T. Kinetic mechanism of competitive adsorption of disperse dye and anionic dye on fly ash. Int. J. Environ. Sci. Technol. 2013, 10 (4), 799-808.

(15) Conkle, J. L.; Lattao, C.; White, J. R.; Cook, R. L. Competitive sorption and desorption behavior for three fluoroquinolone antibiotics in a wastewater treatment wetland soil. Chemosphere 2010, 80 (11), 1353-1359. 
374

375

376

377

378

379

380

381

382

383

384

385

387

388

(16) Xing, B.; Pignatello, J. J. Competitive sorption between 1, 3-dichlorobenzene or 2, 4-dichlorophenol and natural aromatic acids in soil organic matter. Environ. Sci. Technol. 1998, 32 (5), 614-619.

(17) Jones-Lepp, T. L.; Alvarez, D. A.; Englert, B.; Batt, A. L. Pharmaceuticals and Hormones in the Environment. Encycl. Anal. Chem. 2009.

(18) Zhang, T.; Li, B. Occurrence, Transformation, and Fate of Antibiotics in Municipal Wastewater Treatment Plants. Crit. Rev. Environ. Sci. Technol. 2011, 41 (11), 951-998.

(19) Jagtap, S.; Yenkie, M. K.; Labhsetwar, N.; Rayalu, S. Fluoride in drinking water and defluoridation of water. Chem. Rev. 2012, 112 (4), 2454-2466.

(20) Marsac, R.; Martin, S.; Boily, J.-F.; Hanna, K. Oxolinic acid binding at goethite and akaganéite surfaces: implications for aquaculture-induced pollution. Environ. Sci. Technol. 2016, 50 (2), 660-668.

(21) Jaumot, J.; Gargallo, R.; de Juan, A.; Tauler, R. A graphical user-friendly interface for MCR-ALS: a new tool for multivariate curve resolution in MATLAB. Chemom. Intell. Lab. Syst. 2005, 76 (1), 101-110.

(22) Kresse, G.; Hafner, J. Ab initio molecular dynamics for liquid metals. Phys. Rev. B 1993, 47 (1), 558-561.

(23) Kresse, G.; Hafner, J. Norm-conserving and ultrasoft pseudopotentials for first-row and transition elements. J. Phys. Condens. Matter 1994, 6 (40), 8245.

(24) Perdew, J. P.; Burke, K.; Ernzerhof, M. Generalized gradient approximation made simple. Phys. Rev. Lett. 1996, 77 (18), 3865-3868. 
(25) Blöchl, P. E. Projector augmented-wave method. Phys. Rev. B 1994, 50 (24), 17953-17979.

(26) Grimme, S.; Antony, J.; Ehrlich, S.; Krieg, H. A consistent and accurate ab initio parametrization of density functional dispersion correction (DFT-D) for the 94 elements H-Pu. J. Chem. Phys. 2010, 132 (15), 154104.

(27) Rusch, B.; Hanna, K.; Humbert, B. Sorption and transport of salicylate in a porous heterogeneous medium of silica quartz and goethite. Environ. Sci. Technol. 2010, 44 (7), 2447-2453.

(28) Paul, T.; Machesky, M. L.; Strathmann, T. J. Surface complexation of the zwitterionic fluoroquinolone antibiotic ofloxacin to nano-anatase $\mathrm{TiO} 2$ photocatalyst surfaces. Environ. Sci. Technol. 2012, 46 (21), 11896-11904.

(29) Pei, Z.; Shan, X. Q.; Kong, J.; Wen, B.; Owens, G. Coadsorption of ciprofloxacin and $\mathrm{Cu}(\mathrm{II})$ on montmorillonite and kaolinite as affected by solution pH. Environ. Sci. Technol. 2010, 44 (3), 915-920.

(30) Ross, D. L.; Riley, C. M. Aqueous solubilities of some variously substituted quinolone antimicrobials. Int. J. Pharm. 1990, 63 (3), 237-250.

(31) Takács-Novák, K.; Tam, K. Y. Multiwavelength spectrophotometric determination of acid dissociation constants: Part V: microconstants and tautomeric ratios of diprotic amphoteric drugs. J. Pharm. Biomed. Anal. 2000, $21(6), 1171-1182$.

(32) Liu, S. Cooperative adsorption on solid surfaces. J. Colloid Interface Sci. 2015, $450,224-238$. 
418

419

420

421

422

423

424

425

426

427

428

429

430

431

432

433

434

(33) Madey, T. E.; Yates Jr, J. T. Vibrational spectroscopy of molecules on surfaces; Springer Science \& Business Media, 2013; Vol. 1.

(34) Akyuz, S.; Akyuz, T. FT-IR spectroscopic investigations of adsorption of 2-, 3-and 4-pyridinecarboxamide on montmorillonite and saponite from Anatolia. Vib. Spectrosc. 2006, 42 (2), 387-391.

(35) Balci, K.; Akkaya, Y.; Akyuz, S. An experimental and theoretical vibrational spectroscopic study on niflumic acid, a non-steroidal anti-inflammatory drug. Vib. Spectrosc. 2010, 53 (2), 239-247.

(36) Schwarzenbach, R. P.; Escher, B. I.; Fenner, K.; Hofstetter, T. B.; Johnson, C. A.; von Gunten, U.; Wehrli, B. The challenge of micropollutants in aquatic systems. Science 2006, 313 (5790), 1072-1077.

(37) Rotter, S.; Gunold, R.; Mothes, S.; Paschke, A.; Brack, W.; Altenburger, R.; Schmitt-Jansen, M. Pollution-Induced Community Tolerance To Diagnose Hazardous Chemicals in Multiple Contaminated Aquatic Systems. Environ. Sci. Technol. 2015, 49 (16), 10048-10056. 
435

436

437

438

439

440

441

442

443

444

445

446

447

448

449

450

451

452

453

454

455

456

Figure captions

Figure1. Left: $\mathrm{pH}$-adsorption edges of a) NA single $\left([\mathrm{NA}]_{\text {tot }}=20 \mu \mathrm{M}\right)$ and binary $\left([\mathrm{NA}]_{\mathrm{tot}}=[\mathrm{NFA}]_{\mathrm{tot}}=20 \mu \mathrm{M}\right)$ and $\left.\mathrm{b}\right) \mathrm{NFA}$ single $\left([\mathrm{NFA}]_{\mathrm{tot}}=20 \mu \mathrm{M}\right)$ and binary $\left([\mathrm{NFA}]_{\mathrm{tot}}=20 \mu \mathrm{M} ;[\mathrm{NA}]_{\mathrm{tot}}=10\right.$ and $\left.20 \mu \mathrm{M}\right)$ systems on goethite, with $10 \mathrm{mM} \mathrm{NaCl}$. Right: molecular structures of NA and NFA.

Figure 2. a) NA and NFA sorption to goethite for single systems (full symbols) and binary system where $[\mathrm{NA}]_{\text {tot }}=[\mathrm{NFA}]_{\text {tot }}($ empty symbols $)$. NA and NFA concentrations were varied from 0.1 to $40 \mu \mathrm{M}$. For the sake of readability, the behaviour at very low concentrations was shown in the insert. b) $[\mathrm{NFA}]_{\mathrm{ads}}$ vs $[\mathrm{NA}]_{\mathrm{ads}}$ at three experimental conditions: (i) varying both compounds from 0 to $40 \mu \mathrm{M}$ (black), (ii) $[\mathrm{NFA}]_{\text {tot }}=20 \mu \mathrm{M}$, $0<[\mathrm{NA}]_{\mathrm{tot}}<40 \mu \mathrm{M}$ (red), and (iii) $[\mathrm{NA}]_{\mathrm{tot}}=20 \mu \mathrm{M}, 0<[\mathrm{NFA}]_{\mathrm{tot}}<40 \mu \mathrm{M}$ (blue).

Figure 3. NA and NFA molecules co-adsorbed on the diaspore surface, with NA adsorbed as (left) inner sphere $\left(\mathrm{E}_{\mathrm{ads}}(\mathrm{NFA} / \mathrm{NA})=0.07 \mathrm{eV}\right.$, athermic process) and (right) outer sphere $\left(\mathrm{E}_{\mathrm{ads}}(\mathrm{NFA} / \mathrm{NA})=-0.21 \mathrm{eV}\right)$. A negative energy indicates an exothermic process.

Figure 4. ATR-FTIR spectroscopy on goethite. (a) from top to bottom: NA single system, dissolved NA $\left(\mathrm{NA}_{(\mathrm{aq})}\right.$ in $\left.1 \mathrm{M} \mathrm{NaOH}\right), \mathrm{NA}-\mathrm{NFA}$ binary system $\left([\mathrm{NA}]_{\text {tot }}=100\right.$ $\mu \mathrm{M}, 10<[\mathrm{NFA}]_{\text {tot }}<100 \mu \mathrm{M}$; the arrows show increasing $[\mathrm{NFA}]_{\text {tot }}$ ), NFA single system, dissolved NFA ( $\mathrm{NFA}_{(\mathrm{aq})}$ in $\left.1 \mathrm{M} \mathrm{NaOH}\right)$. Bold and thin dashed lines show characteristic bands of $\mathrm{NA}_{(\mathrm{aq})}$ and $\mathrm{NFA}_{(\mathrm{aq})}$, respectively. Numbers denote $[\mathrm{NFA}]_{\text {tot. }}$ Spectra were normalized according to the band at $1448 \mathrm{~cm}^{-1}$, since NA is the major component. 
457 Figure 5. MCR-extracted spectral profiles from FTIR spectra of (a)100 $\mu \mathrm{m}$ NFA + NA,

458 (b) $100 \mu \mathrm{m}$ NA + NFA, both including reference spectra, and (c) associated 459 concentration profiles corresponding to components MCR I and II. These concentration 460 profiles underscore the larger propensity of NA at displacing bound NFA, than NFA at 461 displacing NA. 

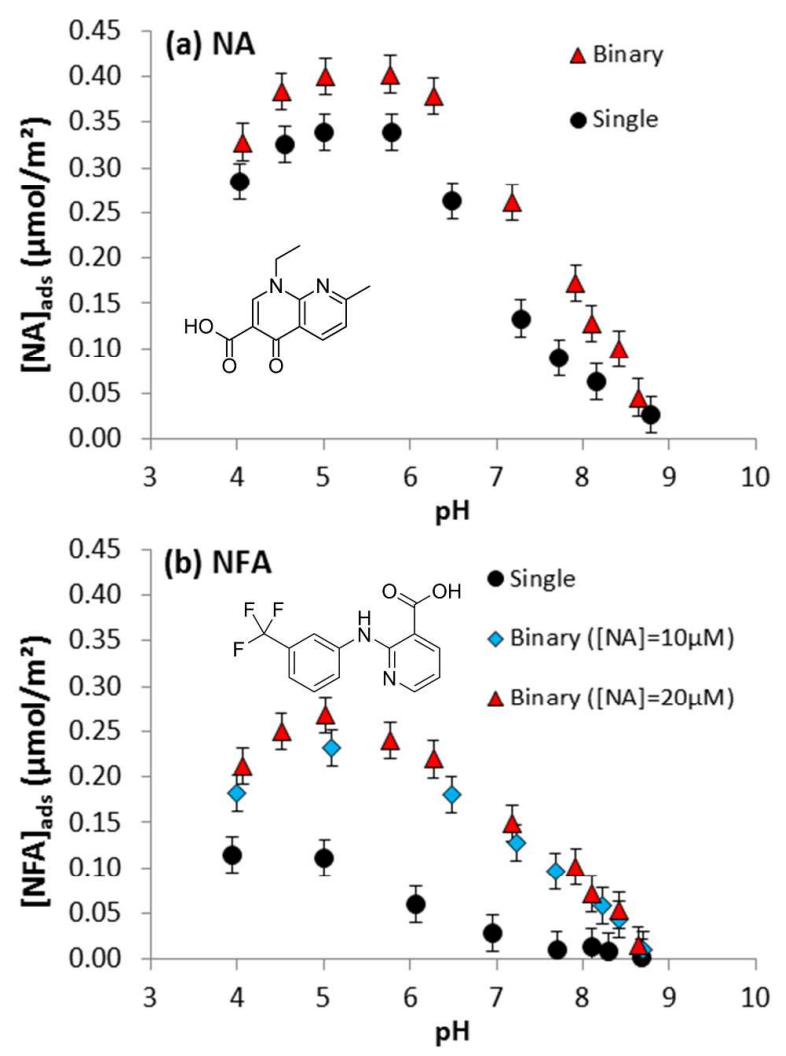

466

Figure 1 

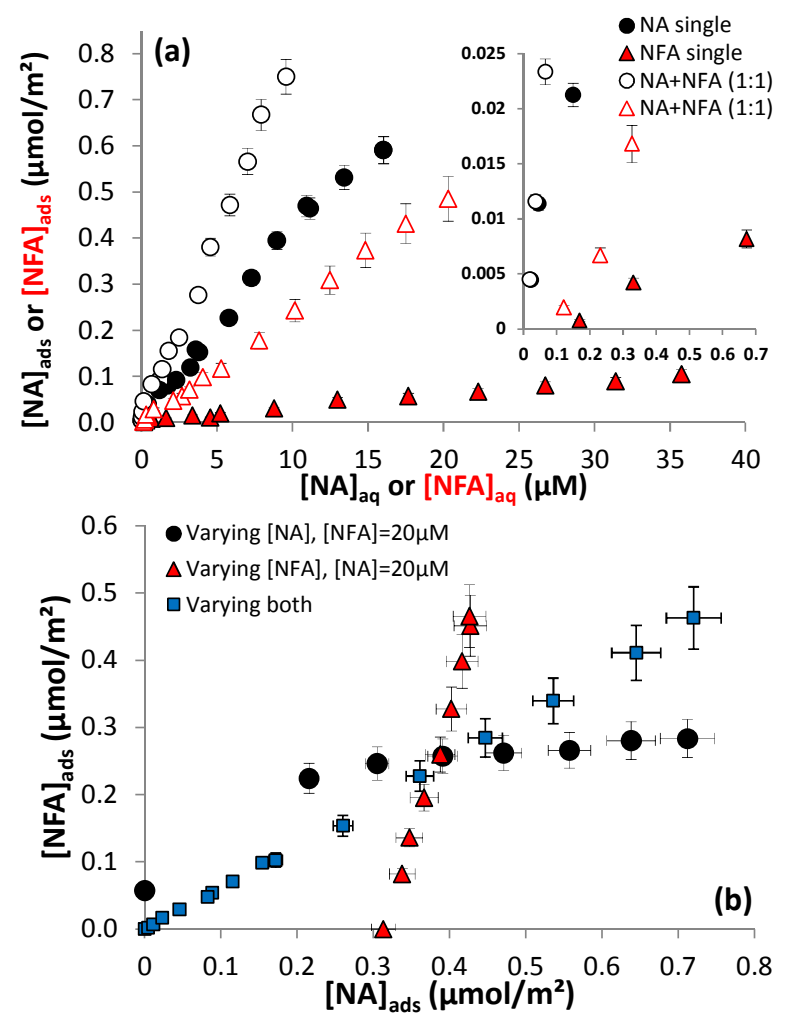

Figure 2

470 
473

474

475

Figure 3

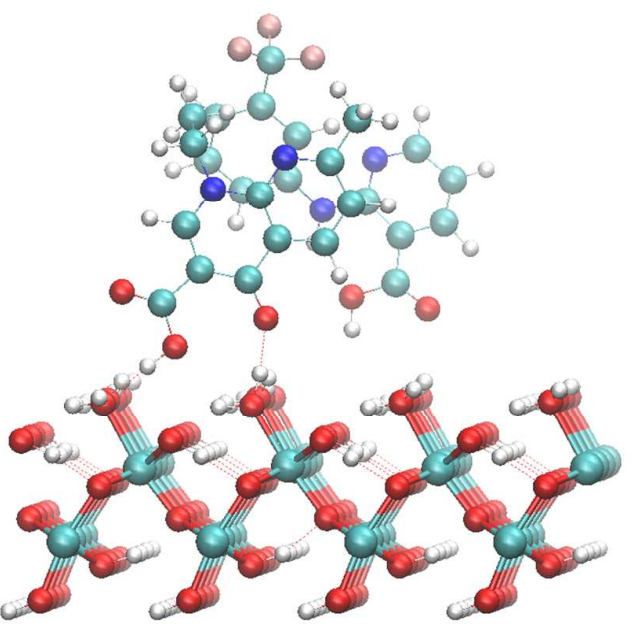




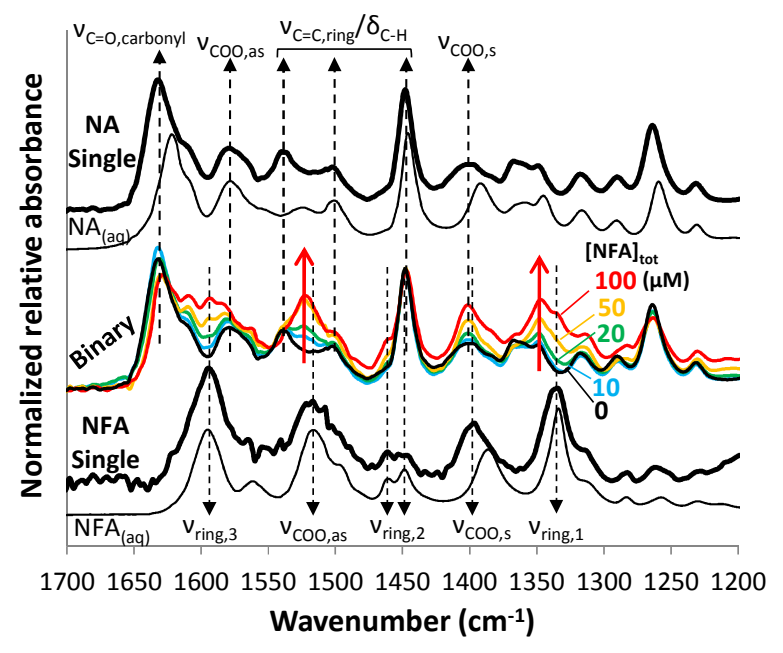

477

Figure 4

478 
a)

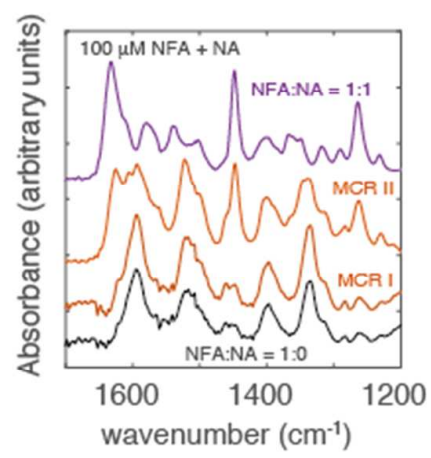

480

481 b)

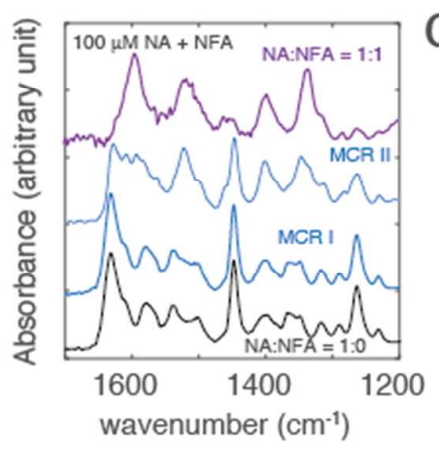

Figure 5

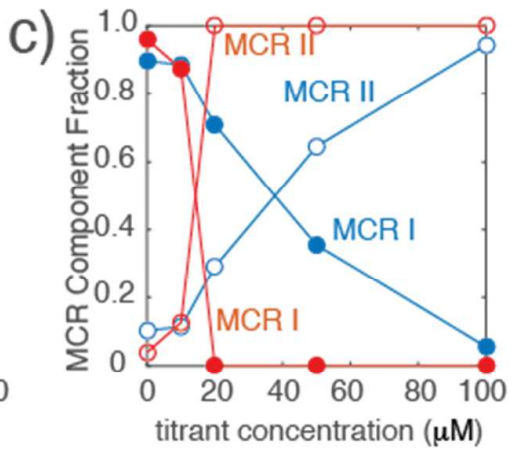




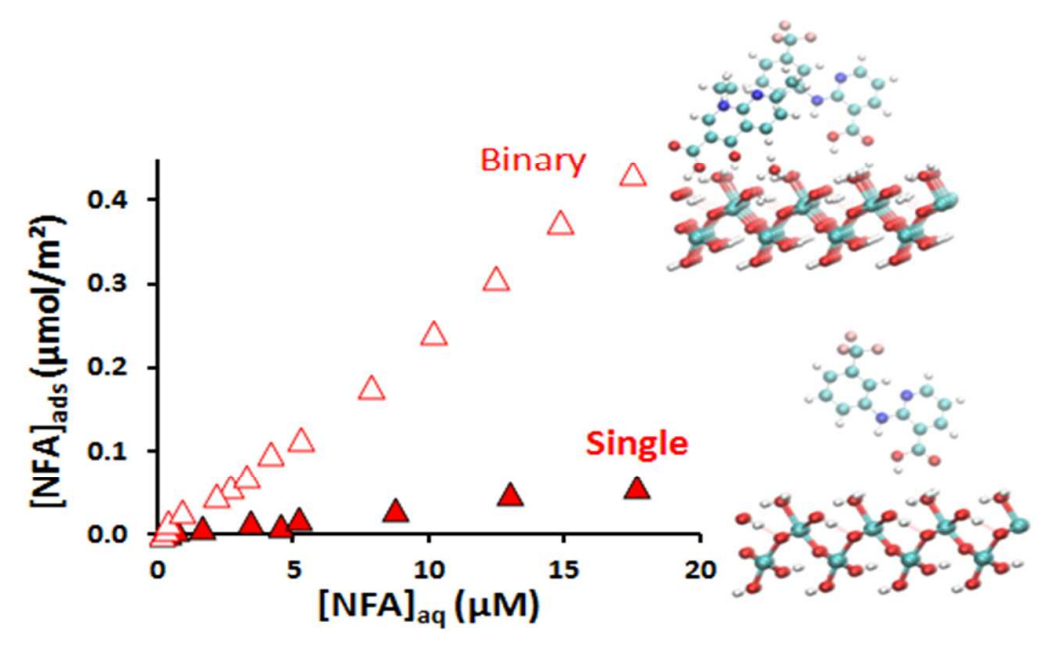

